\title{
Nitrogen Implantation Effects on the Chemical Bonding and Hardness of Boron and Boron Nitride Coatings
}

\author{
Alan Jankowski \\ Thomas Felter \\ Robert Patterson \\ Jeffrey Hayes \\ Simone Anders \\ Thomas Stamler \\ David Poker
}

This paper was prepared for submittal to the

Materials Research Society

Boston, MA

November 30 - December 2, 1998

February 8, 1999

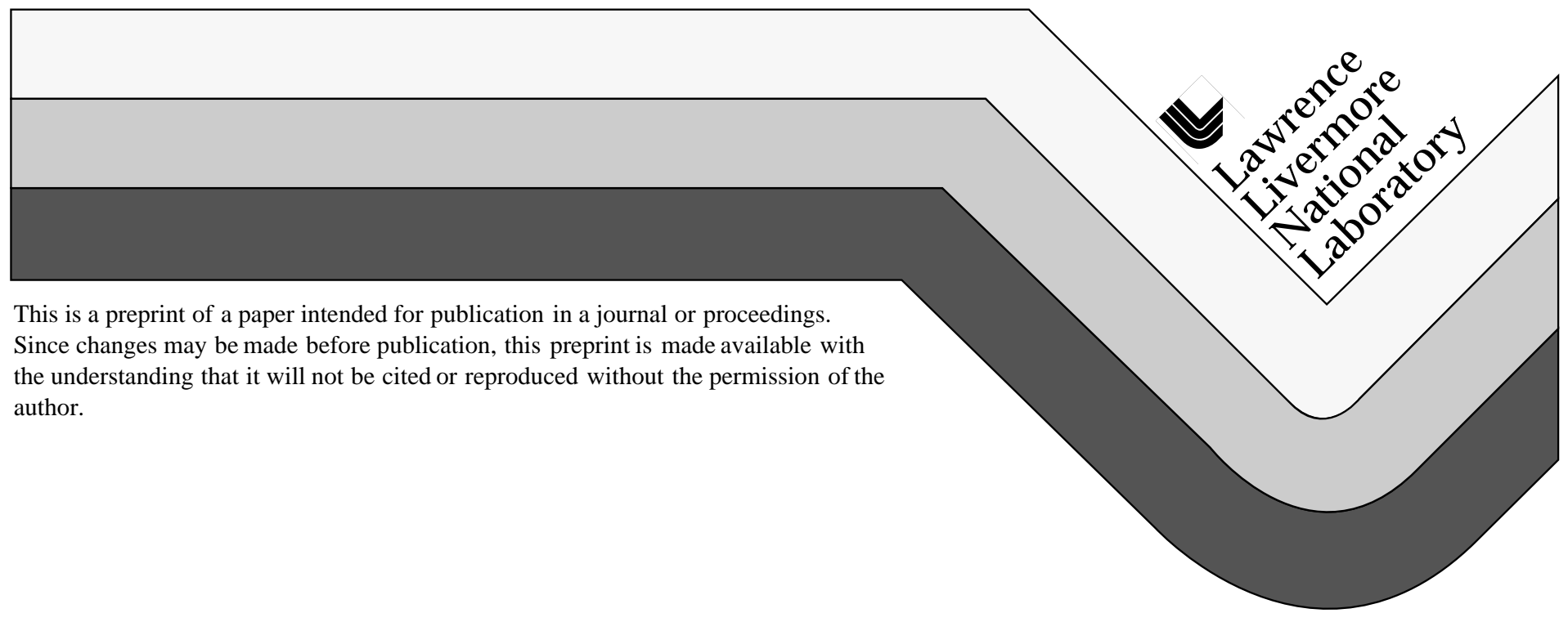




\section{DISCLAIMER}

This document was prepared as an account of work sponsored by an agency of the United States Government. Neither the United States Government nor the University of California nor any of their employees, makes any warranty, express or implied, or assumes any legal liability or responsibility for the accuracy, completeness, or usefulness of any information, apparatus, product, or process

disclosed, or represents that its use would not infringe privately owned rights. Reference herein to any specific commercial product, process, or service by trade name, trademark, manufacturer, or otherwise, does not necessarily constitute or imply its endorsement, recommendation, or favoring by the United States Government or the University of California. The views and opinions of authors expressed herein do not necessarily state or reflect those of the United States Government or the University of California, and shall not be used for advertising or product endorsement purposes. 


\title{
NITROGEN IMPLANTATION EFFECTS ON THE CHEMICAL BONDING AND HARDNESS OF BORON AND BORON NITRIDE COATINGS
}

\author{
Alan Jankowski*, Thomas Felter*, Robert Patterson*, Jeffrey Hayes*, Simone Anders**, \\ Thomas Stamler**, and David Poker*** \\ *Lawrence Livermore National Laboratory, 7000 East Avenue, Livermore, CA 94550 \\ **Lawrence Berkeley National Laboratory, 1 Cyclotron Road, Berkeley, CA 94720 \\ ***Oak Ridge National Laboratory, 1 Bethel Valley Road, Oak Ridge, TN 37831
}

\begin{abstract}
Boron nitride $(\mathrm{BN})$ coatings are deposited by the reactive sputtering of fully dense, boron (B) targets utilizing an argon-nitrogen $\left(\mathrm{Ar}-\mathrm{N}_{2}\right)$ reactive gas mixture. Near-edge $\mathrm{x}$-ray absorption fine structure analysis reveals features of chemical bonding in the B $1 s$ photoabsorption spectrum. Hardness is measured at the film surface using nanoindentation. The BN coatings prepared at low, sputter gas pressure with substrate heating are found to have bonding characteristic of a defected hexagonal phase. The coatings are subjected to post-deposition nitrogen $\left(\mathrm{N}^{+}\right.$and $\left.\mathrm{N}_{2}^{+}\right)$ implantation at different energies and current densities. The changes in film hardness attributed to the implantation can be correlated to changes observed in the B $1 s$ NEXAFS spectra.
\end{abstract}

\section{INTRODUCTION}

Boron nitride $(\mathrm{BN})$ is of interest for use in wear resistant coatings and hard surfaces. The hardness of crystalline films is directly related to the microstructure and chemical bonding within the material. Near-edge x-ray absorption fine structure (NEXAFS) spectroscopy can be used to identify the nature of chemical bonding in a material. For boron and its nitride phases, chemical bonding features are shown to correlate with the hardness of crystalline and nanocrystalline BN as well as amorphous B films. [1-4] Curve fitting the NEXAFS spectra beyond the $\sigma^{*}$-edge can be used to determine the relative $s p^{2}$ and $s p^{3}$ intensities that in turn provides a quantification of the $\mathrm{BN}$ phase content.[1,4] An increase in hardness is found to be proportional with the increase in the cubic boron-nitride (cBN) phase content for sputter deposited BN films. [4]

The variation of deposition conditions (i.e. sputter gas pressure, flow and composition along with substrate temperature and applied bias) affect the formation of crystalline phases in BN films deposited by rf sputtering pure boron targets using unbalanced planar magnetrons. [1,2] Hardness can be influenced by post-deposition treatments as well. A post deposition implantation of boron and boron nitride can reveal the nature of formation and stabilization of the cubic boron nitride (cBN) phase. Ion implantation of hexagonal boron nitride (hBN) with $\mathrm{N}_{2}{ }^{+}$was shown with NEXAFS to induce a significant proportion of $s p^{3}$ bonding characteristic of cBN.[3] A 100-fold variation in hardness appears for BN films that can be characterized by $s p^{2}$ bonding features alone.[2] The presence of defects in the chemical bonding of hBN appear as resonances found beyond the $\pi^{*}$-edge.[3-4] The present objective is to further evaluate the effects of implantation energy and current density on boron and its nitride phases. In particular, to use post deposition implantation to harden $\mathrm{B}$ and hBN coatings.

\section{EXPERIMENTALS}

The BN (no. 417a, 417b and 814) and B (no. 819) samples are prepared using physical vapor deposition. The $0.4-0.8 \mu \mathrm{m}$ thick coatings are deposited by sputtering pure boron using planar magnetrons operated at $200 \mathrm{~W}$ power in the rf mode.[1-2,5] The boron targets are unique in that full $(>99 \%)$ density is achieved with elemental purity $(>0.998)$. Synthesis of the boron sputter targets is described in detail elsewhere.[6] The deposition chamber is cryogenically pumped to a $5 \times 10^{-6} \mathrm{~Pa}$ base pressure. The $\mathrm{B}$ coatings are deposited using $\mathrm{Ar}$ as the working gas whereas the $\mathrm{BN}$ coatings are deposited using a $\mathrm{Ar}-25 \% \mathrm{~N}_{2}$ reactive gas mixture.[5] A 10-20nm thick Cr layer is initially deposited to enhance coating adherence to the $1.2 \times 1.2 \mathrm{~cm}$ silicon substrates. The 
substrates are positioned laterally from the center of the $6.3 \mathrm{~cm}$ diameter target. A substrate temperature of $300^{\circ} \mathrm{C}$ is achieved using a Boralectric ${ }^{\mathrm{TM}}$ heater. A $0.23 \mathrm{~Pa}$ sputter gas pressure is maintained using a $28 \mathrm{~cm}^{3} \mathrm{~min}^{-1}$ total flow rate. Deposition rates of $0.019 \mathrm{~nm} \mathrm{~s}^{-1}$ and $0.025 \mathrm{~nm} \mathrm{~s}^{-1}$ are produced using the $\mathrm{Ar}$ and $\mathrm{Ar}-25 \% \mathrm{~N}_{2}$ sputter gases, respectively. The as-deposited coating thickness $\left(\mathrm{t}_{\mathrm{o}}\right)$ is measured using a Dektak II contact profilometer.

The as-deposited samples are modified by nitrogen implantation. A tantalum shadow mask exposes the center of each coated wafer to the implanted species. Two sets of implants are performed that accentuate the effects of the per nitrogen implant energy and current density. The nitrogen implantations are achieved with a cryogenically pumped Varian 3000 system using a Freeman source. In the first set, the variable is implant energy. A two-pocket shadow mask is used for samples no. 417a and 417b. The terminal potential is set at 90 or $180 \mathrm{keV}$. A selection at the analyzer magnet of 14 atomic mass units (amu) is used for $\mathrm{N}^{+}$ions. These conditions yield 90 or $180 \mathrm{keV}$ per incident nitrogen atom. A $24 \mu \mathrm{A}$ focused beam is rastered across a surface area in excess of $100 \mathrm{~cm}^{2}$ that covers the hard-masked substrates. This exposure condition produces a $5.0 \times 10^{14} \mathrm{~cm}^{-2} \mathrm{~s}^{-1}$ flux of nitrogen atoms, i.e. an equivalent "nitrogen atom" beam current density $\left(\rho_{\mathrm{N}}\right)$ of $81 \mu \mathrm{A} \mathrm{cm}^{-2}$. The total dose of nitrogen atoms at either 90 or $180 \mathrm{keV}$ is $1 \times 10^{17} \mathrm{~cm}^{-2}$. In the second implantation set, the variable is current density with respect to the first implant set. For this implant, a four-pocket shadow mask is used for samples no. 814 and 819. The terminal potential is set at $200 \mathrm{keV}$. A selection at the analyzer magnet of $28 \mathrm{amu}$ is used for $\mathrm{N}_{2}{ }^{+}$ions. These conditions yield $100 \mathrm{keV}$ per incident nitrogen atom. A $15 \mu \mathrm{A}$ defocused beam is rastered across a surface area in excess of $100 \mathrm{~cm}^{2}$ that covers the hardmasked substrates. This exposure condition produces a $1.9 \times 10^{14} \mathrm{~cm}^{-2} \mathrm{~s}^{-1}$ flux of nitrogen atoms, i.e. an equivalent $\rho_{\mathrm{N}}$ of $31 \mu \mathrm{A} \mathrm{cm}^{-2}$. The total dose of nitrogen atoms at $100 \mathrm{keV}$ is $2 \times 10^{17} \mathrm{~cm}^{-2}$. Note that before this implant, the samples received a small $1.4 \times 10^{16} \mathrm{~cm}^{-2}$ dose of $200 \mathrm{keV}\left(\mathrm{N}^{+}\right)$ nitrogen atoms as $14 \mathrm{amu}$ was inadvertantly selected for the implant condition. The change in thickness $(\Delta t)$ found in the implanted region is measured using a Dektak II contact profilometer. A summary of the implant conditions is listed in Table 1 for each sample wherein a suffix is added to each sample no. indicating the implantation energy per nitrogen atom. For example, the $90 \mathrm{keV}$ implanted BN sample no. 417a is designated as 417-90.

Near-edge x-ray absorption fine structure (NEXAFS) spectroscopy provides information about the elemental composition and bonding character of the B and BN samples.[7] NEXAFS spectroscopy is based on the availability of $\mathrm{x}$-ray radiation of tunable wavelength that is produced by a synchrotron. Measurements are taken on beamline 8.0 at the Advanced Light Source (ALS) in Berkeley. This undulator beamline is equipped with a spherical grating monochromator that delivers $\mathrm{x}$-ray radiation in the range of $200-1500 \mathrm{eV}$ with a resolving power of $\mathrm{E} / \Delta \mathrm{E}=10^{4}$. NEXAFS spectroscopy is very sensitive to variations in the local bonding structure of boron nitride, and therefore is a suitable method to study the various phases of boron nitride.[4] Unique spectral features in the boron and nitrogen $1 s$ photoabsorption cross sections correspond with resonances that are specific to discrete $\mathrm{BN}$ phases. [8] The photon energy of monochromatic synchrotron radiation is scanned through the core-level edge while monitoring the electron yield to measure the B $1 s$ core-level photoabsorption cross-section. The low-energy, long mean-free-path electron emission dominates the signal. The transition of $1 s$ initial states into p-like empty final states is associated with $s p^{2}$ hybridized, planar bonding that is characteristic of $\mathrm{hBN}$ and appears as the narrow, intense transition at $192 \mathrm{eV}$. This $\pi^{*}$ resonance is absent in $s p^{3}$ tetrahedrally bonded materials such as $\mathrm{cBN}$ which uniquely evidence an absorption maximum step into $\sigma^{*}$ continuum states above $194 \mathrm{eV}$. The resonance peak at 192 $\mathrm{eV}$ indicates $\mathrm{B}-\left(\mathrm{N}_{3}\right)$ bonding in $\mathrm{hBN}$. The presence of N-void defects in the $\mathrm{hBN}$ structure are representative of $\mathrm{B}-\left(\mathrm{BN}_{2}\right)$ and $\mathrm{B}-\left(\mathrm{B}_{2} \mathrm{~N}\right)$ corresponding to the successive satellite peaks above 192 eV.[3] The diffuse peak for elemental boron at $194 \mathrm{eV}$ can be correlated with some degree of planarization of $s p^{3}$ tetrahedral bonding, similar in signature to the sub-surface boron layer that forms in silicon.[9-10] Local NEXAFS spectra of the implanted and unimplanted region are acquired by averaging over a $50 \mu \mathrm{m}$ diameter region from each sample.

The mechanical properties of the B and BN samples are characterized using nanoindentation. Hardness measurements are performed on a Nano Instruments IIs nanoindenter. A Berkovitz diamond tip that has three-sides, each at $65.3^{\circ}$ to the base, is used to indent the coatings. Force 
measurements at various depths up to 1 micron are repeated between 10 to 15 times, then 
Table I. Samples, Implant Conditions and Properties of B and BN Samples

\begin{tabular}{|c|c|c|c|c|c|c|c|c|c|c|c|}
\hline $\begin{array}{l}\text { Sample } \\
\text { No. }\end{array}$ & Deposit & $\begin{array}{c}\mathbf{t}_{\mathbf{o}} \\
(\mu \mathrm{m})\end{array}$ & Ion & $\begin{array}{l}\text { Energy } \\
\left(\text { keVatom }^{-1}\right)\end{array}$ & $\begin{array}{c}\boldsymbol{\rho}_{\mathbf{N}} \\
\left(\mu \mathrm{Acm}^{-2}\right)\end{array}$ & $\begin{array}{c}\Delta \mathbf{t} \\
(\mathrm{nm})\end{array}$ & $\begin{array}{c}\mathbf{I}_{1} \\
\left(\mathrm{~B}-\mathrm{N}_{3}\right)\end{array}$ & $\begin{array}{c}\mathbf{I}_{\mathbf{2}} \\
\left(\mathrm{B}-\mathrm{BN}_{2}\right)\end{array}$ & $\begin{array}{c}\mathbf{I}_{3} \\
\left(\mathrm{~B}-\mathrm{B}_{2} \mathrm{~N}\right)\end{array}$ & $\begin{array}{l}\mathbf{I}_{4} \\
(\mathrm{~B})\end{array}$ & $\underset{(\mathrm{GPa})}{\mathbf{H}}$ \\
\hline $417 a-0$ & $\mathrm{BN}$ & 0.42 & - & 0 & 0 & 0 & 0.81 & 0.13 & 0.05 & 0.01 & 0.9 \\
\hline $417 a-90$ & $\mathrm{BN}$ & 0.42 & $\mathrm{~N}^{+}$ & 90 & 81 & -270 & 0.43 & 0.28 & 0.18 & 0.11 & 3.4 \\
\hline $417 b-0$ & $\mathrm{BN}$ & 0.42 & - & 0 & 0 & 0 & 0.81 & 0.13 & 0.05 & 0.01 & 0.9 \\
\hline $417 b-180$ & $\mathrm{BN}$ & 0.42 & $\mathrm{~N}^{+}$ & 180 & 81 & -140 & 0.92 & 0.06 & 0.02 & 0.00 & 0.2 \\
\hline $814-100$ & $\mathrm{BN}$ & 0.80 & $\mathrm{~N}_{2}^{+}$ & 100 & 31 & +33 & - & - & - & - & $0.7-4.0$ \\
\hline ref. $[2,10]$ & B & 0.14 & - & 0 & 0 & 0 & 0.00 & 0.01 & 0.03 & 0.96 & 26.4 \\
\hline ref.[5] & B & 6.0 & - & 0 & 0 & 0 & - & - & - & - & 28.3 \\
\hline $819-100$ & $\mathrm{~B}$ & 0.48 & $\mathrm{~N}_{2}^{+}$ & 100 & 31 & +33 & - & - & - & - & 40.1 \\
\hline
\end{tabular}

averaged, and the standard deviations are used to derive the probable errors. Hardness is defined as the average pressure under the indenter tip. Hardness can be calculated from the load divided by the projected area of contact between the tip and the sample. The projected area is determined from the depth of penetration using the known profile of the tip. Since indentation depth is a combination of elastic and inelastic components, a proper derivation of hardness requires the removal of the elastic portion. The detailed computation of hardness from loaddisplacement curves developed for bulk homogeneous materials has continued to evolve to better define parameters such as true contact area that are useful for analyzing stiff materials as well as inhomogeneous systems.[11-12] Although there are limitations imposed by analyzing inhomogeneous and hard materials, hardness is computed using the standard procedure developed from Doerner and Nix.[13-15] The elastic modulus is calculated from the initial linear portion of the unloading curve and extrapolates to zero load.

\section{RESULTS}

The NEXAFS spectra for samples no. 417a-0 (Fig. 1) and 417b-0 compared with reference data from Jiménez, et al.[4,10] show that the unimplanted area exhibits bonding typical of the hexagonal structure with the boron $\pi^{*}$ resonance at $192 \mathrm{eV}$ (peak 1). The spectrum is very similar to published spectra of BN films grown by either pulsed-laser or rf-sputter deposition. [4] The small additional features (peaks 2-4) just above the boron $\pi^{*}$ resonance are correlated with $\mathrm{N}$-void defects in the hexagonal bonding, i.e. with the fact that boron atoms can be bound to three (peak 1), two (peak 2), one (peak 3), or no (peak 4) nitrogen atoms leading to four different peaks at the $\pi^{*}$ resonance. The spectra for a B film is shown for reference.[10] Whereas the spectrum for the $180 \mathrm{keV}$ implant region (sample no. 417b-180 not shown) evidences a very small decrease in the N-void defect peak intensities relative to the unimplanted condition, the spectrum for the $90 \mathrm{keV}$ implant region (sample no. 417a-90) exhibits stronger defect features. No clear formation of the cubic phase is found in the sample no. 417 set of films as is observed when films are deposited by ion-assisted laser deposition at lower $\left(10-70 \mu \mathrm{A} \mathrm{cm} \mathrm{cm}^{-2}\right)$ current densities of nitrogen.[1,4] The peak intensities (I) of the B 1s spectra are quantified for each BN bonding variant, i.e. peaks 1-4. A fitting procedure is applied to deconvolute the $\pi^{*}$ resonance peaks into a superposition of four Gaussian curves.[2-3] The results using this fitting procedure are listed in Table 1 for each sample. NEXAFS spectra await for samples 814 and 819 .

The hardness measured for each sample (Fig. 2) increases with the indenter depth. The hardness values converge to the 9-10 GPa value of the Si substrate beyond an indenter depth equal to the film thickness. To measure the film requires attention to the shallow (about $10 \% \mathrm{t}_{\mathrm{o}}$ ) indentation depths.[16] The average hardness $(\mathbf{H})$ values measured for all B and BN samples are listed in Table 1. The hardest as-deposited sample is the thin B coating. [2] Similar 28 $\pm 1 \mathrm{GPa}$ hardness values are measured for $6 \mu \mathrm{m}$ thick B films using a Vickers micro-indenter.[5] The 
softest sample is implanted BN no. 417b-180. The hardness of an unimplanted region of $\mathrm{BN}$ samples no. $417 \mathrm{a}-90$ and $417 \mathrm{~b}-180$ are equal to the as-deposited value of $0.9 \mathrm{GPa}$ for samples

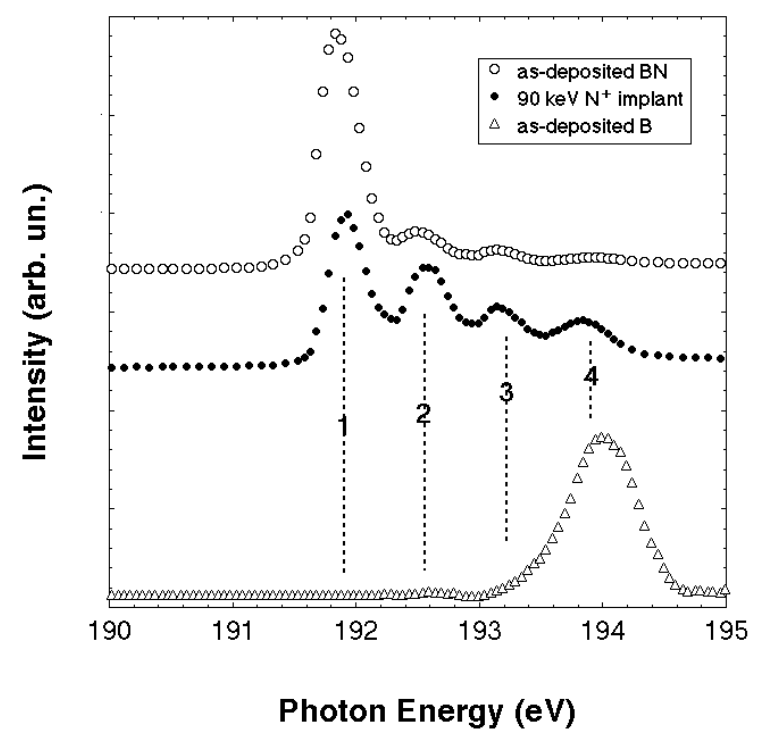

Fig. 1. Electron yield intensity varies with photon energy (eV) in these NEXAFS B $1 s$ spectra for B (ref.)[10], as-deposited BN (417a$0)$ and $90 \mathrm{keV} \mathrm{N}^{+}$implanted $\mathrm{BN}(417 \mathrm{a}-90)$.

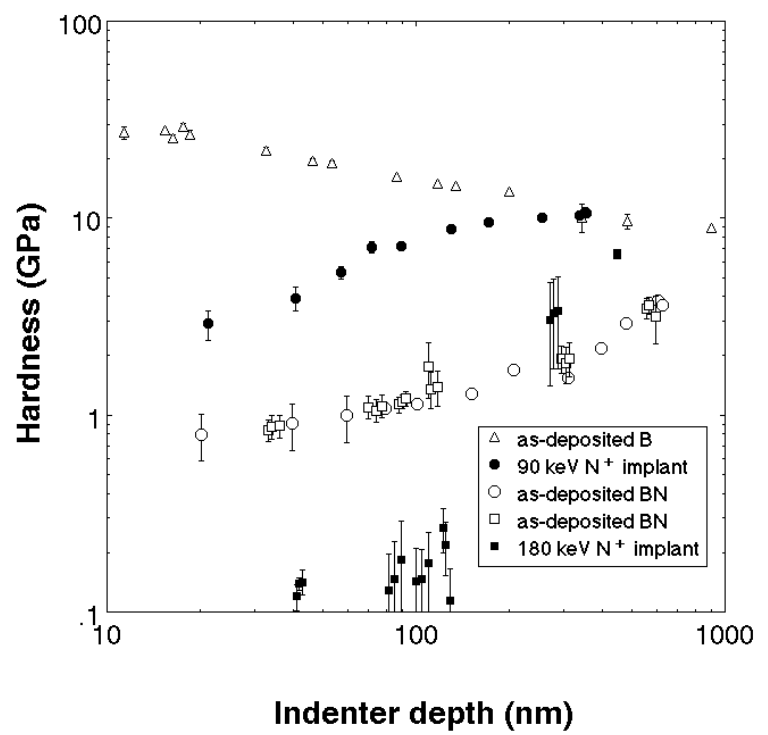

Fig. 2. Hardness $(\mathrm{GPa})$ varies with indenter depth $(\mathrm{nm})$ for $\mathrm{B}$ (ref.)[2], as-deposited $\mathrm{BN}$ (417a-0 and $417 \mathrm{~b}-0)$, and $\mathrm{N}^{+}$implanted $\mathrm{BN}$ at $90 \mathrm{keV}(417 \mathrm{a}-90)$ and $180 \mathrm{keV}(417 \mathrm{~b}-180)$.

no. $417 \mathrm{a}-0$ and $417 \mathrm{~b}-0$ as expected. The $90 \mathrm{keV} \mathrm{N} \mathrm{N}^{+}$implant hardens the $\mathrm{BN}$ coating surface whereas the $180 \mathrm{keV} \mathrm{N}^{+}$implant softens the BN coating surface.

The $200 \mathrm{keV} \mathrm{N}_{2}{ }^{+}$implant shows some unusual results for samples no. 814 and 819 . Most interesting is the $12 \mathrm{GPa}$ increase in hardness measured for B sample no. 819-100. The hardness values do not appear to signifcantly differ between the implanted and unimplanted regions of sample no. 819-100. Since the hardness of B is well-established[2,5] this raises concern to the certainty of the as-deposited region associated with the sample no. 819 hardness measurement. Also, a similar irregularity is found for the hardness measured in the unimplanted region of sample no. 814. A 0.7 to $4 \mathrm{GPa}$ range in hardness is measured for sample no. 814-100. This broad range draws attention to the relative etching and spallation that occurs during implantation. If the soft BN surfaces are hardened by the implant at a low current density, then there will be little etching but perhaps some spallation of the hard surface off the softer base material. Thus, some areas of the implant region (i.e. sample no. 814-100) may appear hard and others soft as the as-deposited BN. If the nitrogen current density is high, thereby annealing the implanted surface, then a significant etching rate may result (as for sample no. 417a-90). Thus, it can be postulated that a $0.7 \mathrm{GPa}$ hardness is likely for sample no. 814-0 as is consistent with all prior measurements for as-deposited BN. The hardness of sample no. 814-100 is likely $\leq 4.0 \mathrm{GPa}$, showing a several-fold increase from the as-deposited condition as is similarly found for the implanted sample no. 417a-90. Cubic BN does not form for any of the implanted BN samples. However, the $200 \mathrm{keV} \mathrm{N}{ }_{2}{ }^{+}$implant of B sample no. 819 may result in some $s p^{3}$ bonding in the BN surface.

\section{DISCUSSION}

The comparative hardness of $\mathrm{BN}$ samples no. $417 \mathrm{a}$ and $417 \mathrm{~b}$ correspond with the relative peak intensities of the $\pi^{*}$ resonances. The hardest films have a strong B peak intensity whereas the softest films have strong B-( $\left.\mathrm{N}_{3}\right)$ bonding. An empirical model is recently developed to directly relate the relative peak intensities to the film hardness.[17] Stabilization of the cBN phase in thin films can be achieved through the use of ion-assisted deposition techniques, e.g. 
high voltage, bias sputtering or ion beam bombardment at the substrate.[18-21] Mechanisms proposed for $\mathrm{cBN}$ stabilization in $\mathrm{BN}$ films include both preferential sputtering effects[22], the presence of large stresses[23-24] and subplantation[25-26] wherein low energy ions are implanted below the surface to increase local density. Post deposition treatments of $\mathrm{hBN}$ are also revealing, as $180 \mathrm{keV} \mathrm{N}_{2}{ }^{+}$ion implantation at a $10 \mu \mathrm{A} \mathrm{cm}^{-2}$ current density induced a significant proportion of $s p^{3}$ bonding characteristic of $\mathrm{cBN}$.[3] Whereas $\mathrm{N}$-void defect introduction to the $\mathrm{BN}$ film is evident in the $\pi^{*}$-resonances, there are no noticeable changes in the $\mathrm{B} 1 s$ spectra beyond the $\sigma^{*}$-edge indicative of $s p^{3}$ bonding at the higher $\left(31\right.$ or $\left.81 \mu \mathrm{A} \mathrm{cm}{ }^{-2}\right)$ current densities used in this study. However, the $31 \mu \mathrm{A} \mathrm{cm} \mathrm{cm}^{-2}$ beam condition may harden the as-deposited BN film more than the $81 \mu \mathrm{A} \mathrm{cm} \mathrm{cm}^{-2}$ beam condition. The effect of current density is also seen in preferential etching, perhaps similar to plasma-assisted chemical vapor deposition processes wherein the growth of the $\mathrm{cBN}$ phase can occur competitively with the selective etching of the $s p^{2}(\mathrm{hBN})$ phase during film growth.[27] Thus it appears an ion current threshold exists for cBN formation. A higher energy $\left(180 \mathrm{keV} \mathrm{N} \mathrm{N}^{+}\right)$ion implant at the greater current density can effectively anneal out the $\mathrm{N}$-void defect structure hence decrease the film hardness. Thus, examination with core level photoabsorption to study BN defects and metastable bonding configurations confirms that the presence of point defects support mechanisms involving defect creation in $\mathrm{cBN}$ formation. [3-4] Recently, similar findings requiring defect generation are found in the mass and energy measurement of species responsible for $\mathrm{cBN}$ growth in rf bias sputter conditions.[28-29]

\section{SUMMARY}

$\mathrm{B}$ and $\mathrm{BN}$ coatings sputter deposited from pure B targets at low gas pressure and temperature are $\mathrm{N}$ ion implanted. The coatings are characterized with NEXAFS and nanoindentation to reveal chemical bonding and surface hardness, respectively. The as-deposited BN coatings have defected hBN bonding and a 0.7-0.9 GPa surface hardness. A high energy, high current density, $\mathrm{N}$ implant etches and softens the BN coatings to a relaxed state of hBN bonding with a $0.2 \mathrm{GPa}$ hardness. A low energy implant hardens the BN coatings with an increase in (N-void) defect structure and an increase in hardness to 3.4-4.0 GPa (where a lower current density enhances the effect). The as-deposited B coating is amorphous $[\mathbf{5 , 1 0 ]}$ and has a $26-28 \mathrm{GPa}$ surface hardness. The low energy, low current density, $\mathrm{N}$ implant hardens the $\mathrm{B}$ coating to $40 \mathrm{GPa}$. Future NEXAFS analysis will probe for the presence of $s p^{3}$ bonding in this $\mathrm{N}$ implanted $\mathrm{B}$ coating. The post deposition, $\mathrm{N}$ implantation yields results similar to ion-beam assisted deposition and ion implantation studies in which stabilization of cBN occurs during growth.[3-4,25-26]

\section{ACKNOWLEDGMENTS}

This work was performed under the auspices of the United States Department of Energy by Lawrence Livermore National Laboratory under contract No. W-7405-Eng-48. This work was supported by the U.S. Department of Energy, Office of Basic Energy Sciences under contract No. DE-AC03-765F00098 and by the Synthesis and Processing Center for Surface Hardness.

\section{REFERENCES}

1. A. Jankowski, J. Hayes, M. MKernan and D. Makowiecki, Thin Solid Films 308-309, p. 94 (1997).

2. A. Jankowski and J.P. Hayes, Diamond Relat. Mater. 7, p. 380 (1997).

3. I. Jiménez, A. Jankowski, L. Terminello, J. Carlisle, D. Sutherland, G. Doll, J. Mantese, W. Tong, D. Shuh and F. Himpsel, Appl. Phys. Lett. 68, p. 2,816 (1996).

4. I. Jiménez, A. Jankowski, L. Terminello, D. Sutherland, J. Carlisle, G. Doll, W. Tong, D. Shuh, and F. Himpsel, Phys. Rev. B 55, p. 12,025 (1997). 
5. M. MKernan, D. Makowiecki, P. Ramsey and A. Jankowski, Surf. Coatings Technol. 49, p. 411 (1991).

6. D. Makowiecki and M. MKernan, Fabrication of Boron Sputter Targets, U.S. Patent No. 5,392,981 (February 28, 1995).

7. J. Stöhr, NEXAFS Spectroscopy, Springer, New York, NY (1992).

8. L. Terminello, A. Chaiken, D. Lapiano-Smith, G. Doll and T. Sato, J. Vac. Sci. Technol. A 12, p. 2,462 (1994).

9. A. MLean, L. Terminello and F. Himpsel, Phys. Rev. B 41, p. 7,694 (1990).

10. A. Jankowski, I. Jiménez, J. Hayes, D. Shuh, D. Sutherland, J. Carlisle, L. Terminello and F. Himpsel, in Applications of Synchrotron Radiation to Materials Science III, edited by L. Terminello, S. Mini, D. Perry and H. Ade (Mater. Res. Soc. Proc. 437, Pittsburgh, PA, 1996), p. 207-210.

11. J. Loubet, J. Georges and J. Meille, in Microindentation Techniques in Materials Science and Engineering, edited by P. Blau and B. Lawn (American Society for Testing and Materials, Philadelphia, PA, 1986), p. 72-89.

12. S. Hainsworth, H. Chandler and T. Page, J. Mater. Res. 11, p. 1,987 (1996).

13. M. Doerner and W. Nix, J. Mater. Res. 1, p. 601 (1986).

14. G. Pharr, W. Oliver and F. Brotzen, J. Mater. Res. 7, p. 613 (1992).

15. W. Oliver and G. Pharr, J. Mater. Res. 7, p. 1,564 (1992).

16. ASTM Standard E 92, in Annual Book of Standards 3.01, American Society for Testing and Materials, Philadelphia, PA, p. 264 (1987).

17. A. Jankowski, Thin Solid Films, in press (1998).

18. D. Kester, K. Alley, D. Lichtenwainer and R. Davis, J. Vac.Sci.Technol. A12, p.3074 (1994).

19. T. Friedmann, P. Mirkarimi, D. Medlin, K. MCarty, E. Klaus, D. Boehme, H. Johnsen, M. Mills, D. Ottesen and J. Barbour, J. Appl. Phys. 76, p. 3,088 (1994).

20. T. Wada and N. Yamashita, J. Vac. Sci. Technol. A 10, p. 515 (1992).

21. N. Tanabe, T. Hayashi and M. Iwaki, Diamond Relat. Mater. 1, p. 883 (1992).

22. S. Reinke, M. Kuhr and W. Kulisch, Diamond Relat. Mater. 3, p. 341 (1994).

23. D. $\mathrm{M}^{\mathrm{c}}$ Kenzie, W. MFall, W. Sainty, C. Davis and R. Collins, Diamond Relat. Mater. 2, p. 970 (1993).

24. D. Medlin, T. Friedmann, P. Mirkarimi, P. Rez, M. Mills and K. Mㄷarty, J. Appl. Phys. 76, p. 295 (1994).

25. J. Robertson, Diamond Relat. Mater. 5, p. 519 (1996).

26. S. Ulrich, J. Schwan, W. Donner and H. Ehrhardt, Diamond Relat. Mater. 5, p. 548 (1996).

27. I. Konyashin, J. Loeffler, J. Bill and F. Aldinger, Thin Solid Films 308-309, p. 101 (1997).

28. Y. Yamada, Y. Tatebayashi, O. Tsuda and T. Yoshida, Thin Solid Films 295, p. 137 (1997).

29. O. Tsuda, Y. Tatebayashi, Y.Yamada-Takamura and T. Yoshida, J. Vac. Sci. Tecnol. A 15, p. 2,859 (1997). 